\title{
Feature Selection pada Azure Machine Learning untuk Prediksi Calon Mahasiswa Berprestasi
}

\author{
Hana Ariesta ${ }^{1}$, Maria Angela Kartawidjaja ${ }^{1}$
}

\begin{abstract}
Universities can not only depend on digital marketing capabilities that are currently widely used but also utilize emerging technologies such as predictive analytics. This research attempts to make a predictive basis for analytic applications by utilizing Azure Machine Learning. In addition to utilizing machine learning capabilities, the author tries to use Feature Selection which is provided to obtain attributes that support research goals related to the world of education. This research aims to find relevant factors for outstanding student candidates for every student admission process. This research uses the Support Vector Machine Algorithm and comparison of the Feature Selection using Pearson Correlation Coefficient and Mutual Information. The results obtained using 10 attributes obtained the best results of 0.827 for accuracy and 0.831 for precision.
\end{abstract}

KEYWORDS: Azure, Machine Learning, Outstanding Students, Predictive, SVM

ABSTRAK: Institusi pendidikan tidak boleh hanya bergantung pada kemampuan digital marketing yang saat ini banyak digunakan namun juga memanfaatkan teknologi yang sedang berkembang seperti predictive analytic. Penelitian ini mencoba membuat dasar aplikasi predictive analytic dengan memanfaatkan Azure Machine Learning. Selain memanfaatkan kemampuan machine learning, penulis mencoba menggunakan Feature Selection yang disediakan untuk memperoleh atribut yang mendukung tujuan penelitian terkait dunia pendidikan. Penelitian ini bertujuan menemukan faktor yang relevan untuk calon mahasiswa berprestasi pada setiap penerimaan mahasiswa baru yang dilakukan. Penelitian ini menggunakan Algoritma Support Vector Machine serta perbandingan Feature Selection menggunakan Pearson Correlative Coefficient dan Mutual Information. Hasil yang diperoleh menggunakan 10 atribut memperoleh hasil terbaik 0.827 untuk accuracy dan 0.831 untuk precision.

KATA KUNCI: Azure, Machine Learning, Mahasiswa Berprestasi, Prediksi, SVM.

\section{PENDAHULUAN}

$\mathrm{P}$ enerimaan mahasiswa baru pasti menjadi prioritas dalam setiap institusi pendidikan. Persaingan dalam bisnis pendidikan semakin ketat sehingga tidak mengherankan jika promosi yang semakin kreatif menjadi sesuatu yang penting. Tantangan dalam dunia marketing adalah bagaimana menekan atau mengurangi biaya untuk promosi dan mengoptimalkan sumber daya institusi yang tersedia dengan cara yang tepat dan bermanfaat. Untuk mengatasi hal tersebut, institusi dapat memanfaatkan teknologi yang sekarang ini sedang berkembang yaitu learning analytic. Teknologi ini sudah banyak digunakan dalam dunia bisnis seperti meningkatkan pertumbuhan investasi, mencari tren selera atau gaya hidup yang sedang terjadi dalam masyarakat, dan masih banyak lainnya. Namun dalam dunia edukasi teknologi ini lebih digunakan untuk memonitor atau mengukur kemajuan siswa. Jika dilihat lebih jauh, peluang memanfaatkan teknologi learning analytic untuk memprediksi keberhasilan atau menentukan strategi marketing yang memungkinkan.

Untuk mengembangkan dan mempelajari mengenai learning analytic membutuhkan penggunaan machine learning untuk membentuk model prediksi dari data yang sudah diolah. Berdasarkan kemampuan dari machine learning, penelitian yang akan dibuat ini berpotensi meningkatkan kualitas pengolahan data yang saat ini masih kurang optimal. Contoh sumber data yang dapat diolah antara lain dari hasil history penelusuran situs web resmi universitas, data pertanyaan seputar admisi, dan juga data akademis seperti data nilai rapor dari calon mahasiswa yang mendaftar, data indeks prestasi mahasiswa dan lama studi mahasiswa. Berdasarkan data tersebut, algoritma machine learning memungkinkan untuk menghasilkan model prediksi calon mahasiswa berprestasi yang dapat digunakan untuk menambah jumlah mahasiswa baru pada universitas.

Tujuan penelitian ini untuk membangun sebuah model prediksi data serta memperoleh faktor relevan yang berpengaruh terhadap data calon mahasiswa yang mendaftar penerimaan mahasiswa baru melalui jalur bebas tes dan berpotensi memiliki performa yang baik di tahun pertama kuliah. Dari hasil tersebut dapat menambah suatu bentuk digital marketing baru untuk universitas. Tim marketing nantinya dapat langsung menggunakan data untuk menawarkan potongan SPP atau beasiswa agar tertarik untuk mendaftar ke universitas

Pengolahan data yang besar membutuhkan alat bantu untuk menganalisis data menjadi pengetahuan yang mendukung kemajuan perguruan tinggi di masa yang akan datang. Teknologi yang banyak digunakan saat ini mengacu pada cloud computing. Pengguna dapat memanfaatkan hasil pengolahan, analisis dan menyimpan data pada satu sumber yang sama. Teknologi cloud computing dibagi menjadi tiga tingkatan yaitu: infrastructure as a service (IaaS), platform as a service (PaaS) dan software as a service (SaaS) seperti ditunjukkan pada Gambar 1.

\footnotetext{
${ }^{1}$ Magister Teknik Elektro, Universitas Katolik Indonesia Atma Jaya
} 


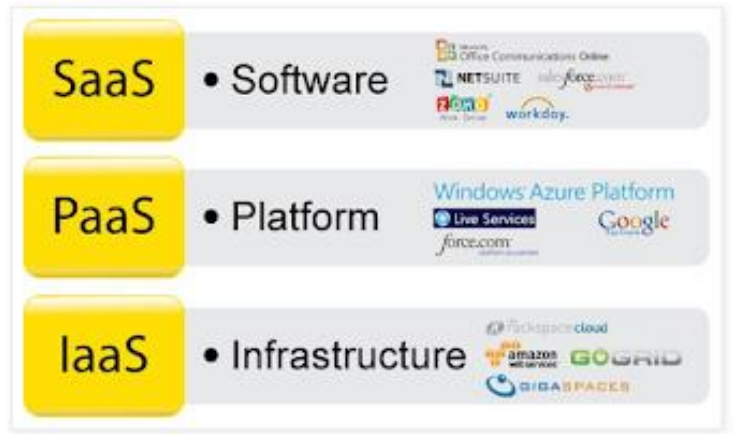

- Gambar 1. Arsitektur Cloud Computing

Sudah banyak penyedia layanan teknologi cloud computing seperti Amazon Web Services (AWS), Google Cloud Services, Microsoft Azure dan lainnya [8].

\section{MACHINE LEARNING}

\section{KAJIAN PUSTAKA}

Machine learning merupakan salah satu sub bagian pembelajaran dari kecerdasan buatan yang memungkinkan sistem memiliki kemampuan untuk "belajar secara otomatis". Machine learning dapat meningkatkan kemampuan berdasarkan pengalaman tanpa perlu diprogram secara eksplisit atau tanpa perlu intervensi manusia. Machine learning harus terlebih dahulu diberikan data untuk dapat dipelajarinya.

Machine learning memiliki sejumlah metode pembelajaran. Secara umum, machine learning diklasifikasikan ke dalam empat kategori, yaitu Supervised Learning, Unsupervised Learning, Semi Supervised Learning dan Reinforcement Learning.

Penelitian ini akan menggunakan Supervised Learning. Dalam penelitian ini proses yang dilakukan dibagi menjadi beberapa tahap, yaitu tahap data preprocessing, tahap pembersihan data, tahap penentuan atribut (feature), tahap klasifikasi, dan tahap evaluasi.

\section{TAHAP DATA PREPROCESSING}

Pada tahap ini, data yang akan digunakan untuk penelitian dikumpulkan dalam satu sumber sehingga memudahkan dalam menghubungkan data antar tabel yang berbeda. Sumber data yang digunakan dalam penelitian ini didapat melalui data mahasiswa yang ada di Biro Administrasi Akademik Universitas Katolik Atma Jaya Jakarta pada angkatan tahun 2011 hingga 2013 untuk Fakultas Teknik, Fakultas Kedokteran dan Fakultas Teknobiologi.

\section{PEMBERSIHAN DATA}

Dalam proses ini akan diperiksa kembali jika terdapat data-data yang belum lengkap atau tidak akurat lebih baik tidak digunakan. Pembersihan data ini akan mempengaruhi performa perhitungan sesuai algoritma yang digunakan karena mengurangi kompleksitas. Data yangmempunyai nilai sama atau redundan akan dihapus. Begitu pula data yang tidak konsisten dan tidak lengkap (missing value). Pada penelitian ini, data yang tidak lengkap akan diisi dengan nilai rata-rata dari kolom data yang kosong tersebut.

\section{TAHAP PENENTUAN ATRIBUT (FEATURE)}

Penelitian ini menggunakan salah satu metode feature selection dalam Azure Machine Learning yaitu Pearson Correlation Coefficient dan Mutual Information dalam membantu memilih atribut yang mempunyai korelatif terkait tujuan penelitian.

\section{TAHAP KLASIFIKASI}

Penelitian ini menggunakan model klasifikasi supervised learning untuk mengevaluasi performa dari model machine learning ini karena menggunakan data yang berlabel. Untuk algoritma yang digunakan adalah Support Vector Machine (SVM).

\section{TAHAP EVALUASI}

Dalam tahap ini dilakukan pengujian untuk mencari dan membandingkan jumlah atribut sesuai skenario yang akan disusun menggunakan algoritma yang sudah dipilih yaitu SVM.

Confusion matrix adalah suatu metode yang biasanya digunakan untuk melakukan perhitungan akurasi pada konsep data mining. Hasil evaluasi calon mahasiswa berprestasi ini dapat dilihat menggunakan confusion matrix seperti pada paper Sembiring dan timnya (Sembiring, dkk., 2011). Tingkat akurasi dan tingkat kesalahan prediksi menunjukkan performa algoritma klasifikasi. Confusion matrix mempunyai empat bagian, yaitu true positive, true negative, false positive dan false negative seperti pada Tabel 1. 
- Tabel 1 Confusion Matrix [7]

\begin{tabular}{ccc}
\hline & \multicolumn{3}{c}{ Prediksi } \\
\cline { 2 - 3 } & Positive & Negative \\
\hline Positive & True Positive $(T P)$ & False Negative (FN) \\
\hline Negative & False Positive $(F P)$ & False Negative $(F N)$ \\
\hline
\end{tabular}

Akurasi merupakan jumlah prediksi benar dari semua data yang diprediksi yang dapat dihitung menggunakan rumus:

Akurasi $(\%)=\frac{T P+T N}{T P+F P+F N+T N}$

Performa keakurasian diklasifikasikan menjadi beberapa kelompok yaitu:

a) nilai AUC $0.90-1.00=$ Unggul

b) nilai AUC $0.80-0.90=$ Baik

c) nilai AUC $0.70-0.80=$ Cukup

d) nilai AUC $0.60-0.70=$ Kurang

e) nilai AUC $0.50-0.60=$ Gagal

\section{MICROSOFT AZURE}

Microsoft Azure adalah suatu platform yang ditawarkan oleh perusahaan Microsoft untuk mengolah dan menganalisis data terutama data yang banyak melalui jaringan global. Untuk mengantisipasi meningkatnya data maka Microsoft menawarkan layanan yang disebut dengan Microsoft Azure. Untuk menangani analisis prediktif (predictive analysis), layanan yang ditawarkan adalah Azure Machine learning. Layanan ini tidak hanya menyediakan alat untuk memodelkan analisis prediktif, namun juga menyediakan layanan yang memungkinkan pengguna untuk mengelola model prediksi yang sudah dibangun.

\section{FEATURE SELECTION}

Feature selection digunakan dalam tahap data preprocessing untuk mengetahui fitur yang paling signifikan dan intrinsik. Dalam Microsoft Azure, terdapat beberapa metode untuk melakukan feature selection yaitu: $C h i-$ square, Pearson Correlation Coefficient, dan Mutual Information seperti dipaparkan dalam jurnal IEEE oleh Punlumjeak [10]. Pada penelitian ini akan membandingkan antara Pearson Correlation Coefficient dan Mutual Information.

\section{PEARSON CORRELATION COEFFICIENT}

Pearson Correlation Coefficient adalah pengukuran statistik, yang mengukur kekuatan hubungan antara distribusi nilai fitur $\mathrm{x}$ dan label kelas c. Pearson Correlation Coefficient didefinisikan sebagai Persamaan sebagai berikut:

$$
\begin{gathered}
\rho(X, C)=\frac{E(X C)-E(X) E(C)}{\sqrt{\sigma^{2}(X) \sigma^{2}(C)}} \\
\rho(X, C)=\frac{\sum_{i}\left(x_{i}-\bar{x}_{i}\right)\left(c_{i}-\bar{c}_{i}\right)}{\sqrt{\sum_{i}\left(x_{i}-\bar{x}_{i}\right)^{2} \Sigma_{j}\left(c_{j}-\overline{c_{j}}\right)^{2}}}
\end{gathered}
$$

$\rho(X, C)= \pm 1$, jika nilai fitur $\mathrm{X}$ bergantung linier. Di sisi lain, jika tidak berkorelasi dianggap nol.

\section{MUTUAL INFORMATION}

Dua variabel acak pada Mutual Information adalah variabel yang saling bergantung jika dalam teori informasi. Dua variabel acak diskrit X dan Y dalam Mutual Information dapat didefinisikan pada Persamaan (4):

$$
I(X ; Y)=\sum_{x, y} P x y(x, y) \log \frac{P x y(x, y)}{P x(x) P y(y)}
$$




\section{SUPPORT VECTOR MACHINE (SVM)}

Support Vector Machine adalah suatu teknik untuk melakukan prediksi, baik dalam kasus klasifikasi maupun regresi. SVM memiliki prinsip dasar linear classifier yaitu kasus klasifikasi yang secara linier dapat dipisahkan, namun SVM telah dikembangkan agar dapat bekerja pada problem non-linier dengan memasukkan konsep kernel pada ruang kerja berdimensi tinggi. Pada ruang berdimensi tinggi, akan dicari hyperplane yang dapat memaksimalkan jarak (margin) antara kelas data. Hyperplane klasifikasi linier SVM dinotasikan pada persamaan 5:

$$
\mathrm{F}(\mathrm{x})=\mathrm{WT} \mathrm{x}+\mathrm{b}
$$

Support Vector Machine (SVM) didefinisikan sebagai seperangkat metode pembelajaran terkait yang menganalisis data dan mengenali pola, yang kemudian digunakan untuk klasifikasi dan analisis regresi. SVM mengambil satu set data input dan memprediksi untuk setiap masukan yang diberikan, yang berasal dari dua kelas yang kemudian di klasifikasikan dengan mencari nilai hyperplane terbaik [6].

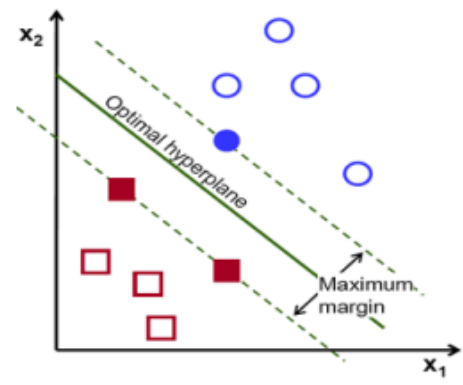

- Gambar 2. SVM Classification with optimal

\section{METODOLOGI}

Tahap awal penelitian pada platform Azure, dibuat sebuah percobaan baru pada menu Experiment dalam Machine Learning Studio seperti ditunjukkan pada Gambar 3.

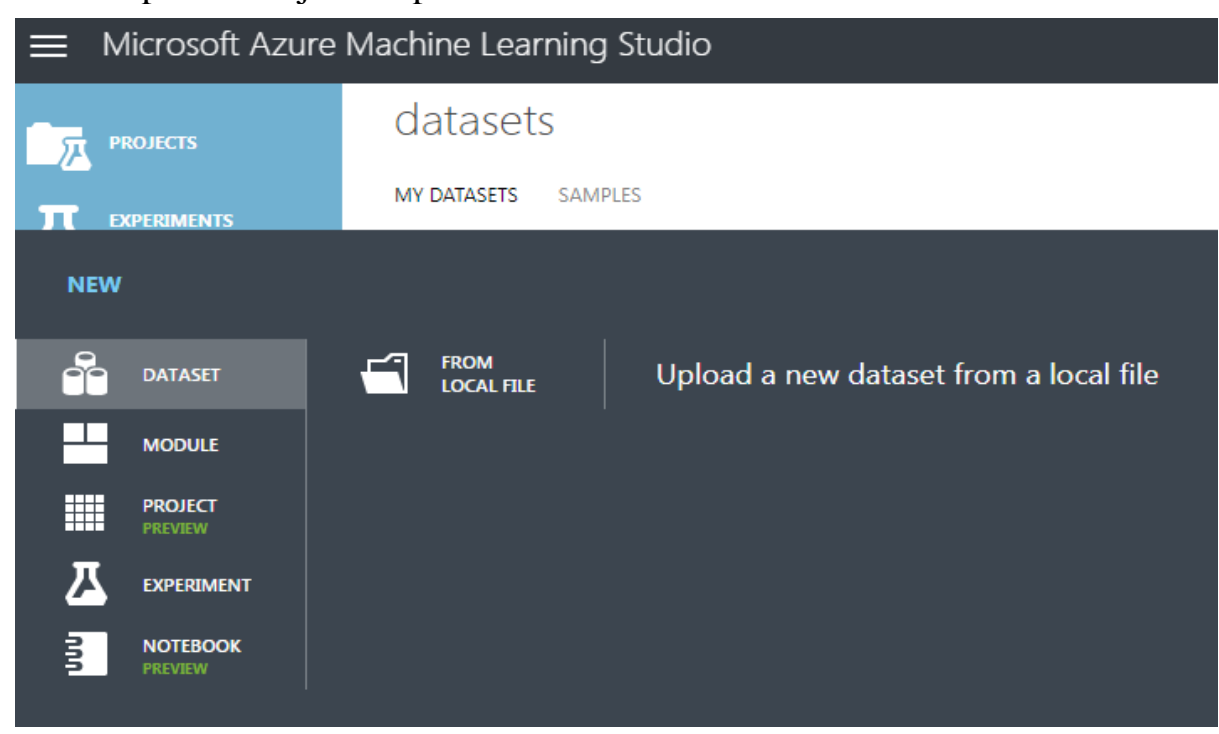

- Gambar 3. Menu Dataset pada Azure Machine Learning

Sebelum membuat sebuah percobaan, disiapkan suatu dataset atau data yang akan digunakan pada percobaan terlebih dahulu. Dataset dapat diunggah pada menu Dataset dengan menyesuaikan format yang didukung oleh Microsoft Azure Machine Learning. Pada penelitian ini, penulis menggunakan format .csv. Setelah dataset siap, langkah selanjutnya adalah memilih dataset mana yang akan digunakan. Tampilan halaman utama pada Menu Experiment Azure Machine Learning dapat dilihat pada Gambar 4. 


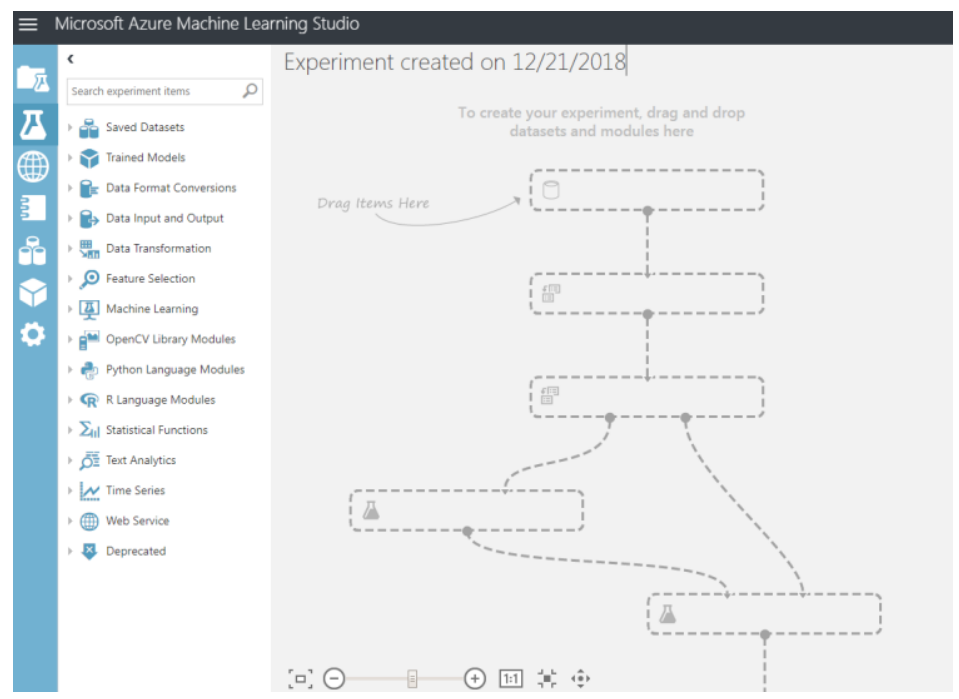

Gambar 4. Tampilan Halaman Utama membuat Percobaan

Tahap berikutnya membagi data menjadi data train dan data model. Variabel perbandingan data train dan data model dapat diatur sesuai kebutuhan. Pada penelitian ini, penulis membuat perbandingan data latih dan data uji sebesar $75 \%: 25 \%$. Dari total data awal sebanyak kurang lebih 800 data, maka dibagi menjadi 600 data sebagai data latih (train data) dan 200 data sebagai data uji (testing data). Untuk atribut, penelitian ini menggunakan 10 atribut dan 2 label dengan deskripsi masing-masing seperti ditunjukkan dalam Tabel 2 dan Tabel 3.

- Tabel 2 Daftar Atribut

\begin{tabular}{ccc}
\hline No. & Nama Atribut & Deskripsi \\
\hline 1 & GPA 1 & Rata-rata GPA pada semester $1 \& 2$ \\
\hline 2 & GPA 2 & Rata-rata GPA semester $3 \& 4$ \\
\hline 3 & CGPA & GPA saat lulus. \\
\hline 4 & MAT & Rata-rata nilai Matematika Kelas 10 \& 11 \\
\hline 5 & KIM & Rata-rata nilai Kimia Kelas $10 \& 11$ \\
\hline 6 & FIS & Rata-rata nilai Fisika Kelas $10 \& 11$ \\
\hline 7 & BIO & Rata-rata nilai Biologi Kelas 10 \& 11 \\
\hline 8 & Ekskul & Aktif di Ekstrakurikuler \\
\hline 9 & OSIS & Aktif di OSIS \\
\hline 10 & Scholarship & Penerima beasiswa \\
\hline
\end{tabular}

Tabel 3 Label Data

\begin{tabular}{c}
\hline Label \\
\hline Lulus Tepat Waktu \\
\hline Tidak Lulus Tepat Waktu
\end{tabular}

Pada penelitian ini, label yang digunakan dibagi menjadi dua kategori yaitu lulus tepat waktu dan tidak lulus tepat waktu. Untuk lulus waktu perhitungannya diambil dari tahun masuk sampai tahun lulus tidak lebih dari 4 tahun atau 8 semester dan sebaliknya untuk kategori tidak lulus tepat waktu diambil dari hasil yang lulus lebih dari 4 tahun atau 8 semester.

Pada penelitian ini, algoritma yang digunakan adalah Support Vector Machine (SVM) dengan menggunakan metode Pearson Correlation Coefficient dan Mutual Information pada feature selection yang dilakukan pada proses data preprocessing. Diagram Alur percobaan yang dibuat pada Azure Machine Learning Studio dapat dilihat pada Gambar 5. 


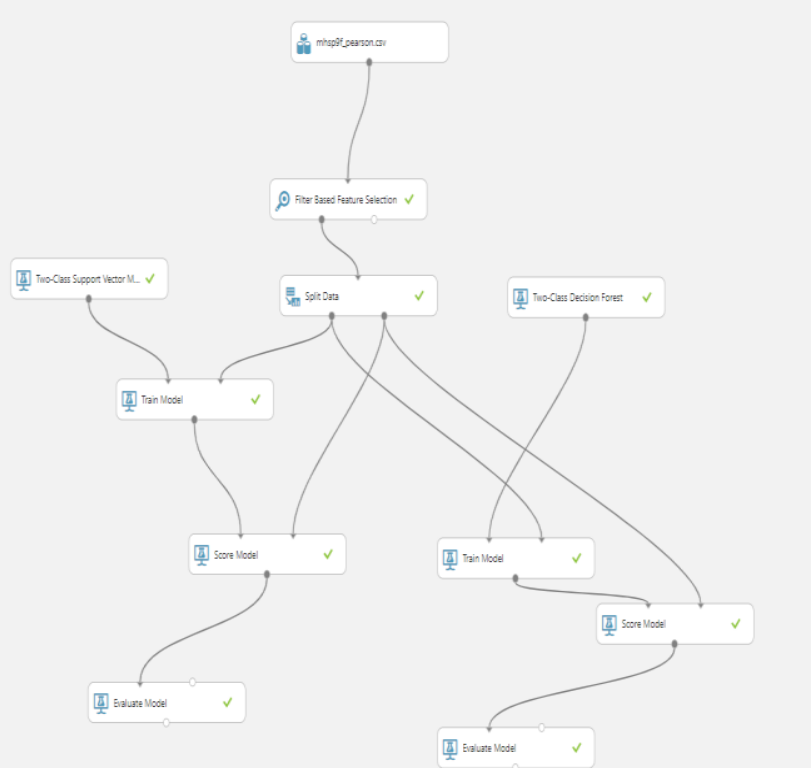

- Gambar 5. Diagram Alur Percobaan pada Azure Machine Learning

Percobaan ini akan membandingkan kinerja algoritma Support Vector Machine dengan jumlah atribut yang berbeda yaitu 6 atribut, 8 atribut, dan 10 atribut. Penelitian ini menggunakan enam skenario tampak pada tabel 4 . 
Tabel 4 Daftar Skenario

\begin{tabular}{cll}
\hline No. & Skenario & Feature Selection \& Jumlah Atribut \\
\hline 1 & Skenario 1 & Pearson - 6 Atribut \\
\hline 2 & Skenario 2 & MI - 6 Atribut \\
\hline 3 & Skenario 3 & Pearson - 8 Atribut \\
\hline 4 & Skenario 4 & MI - 8 Atribut \\
\hline 5 & Skenario 5 & Pearson - 10 Atribut (All) \\
\hline 6 & Skenario 6 & MI - 10 Atribut (All) \\
\hline
\end{tabular}

Tabel 5. Confusion Matrix Skenario 1

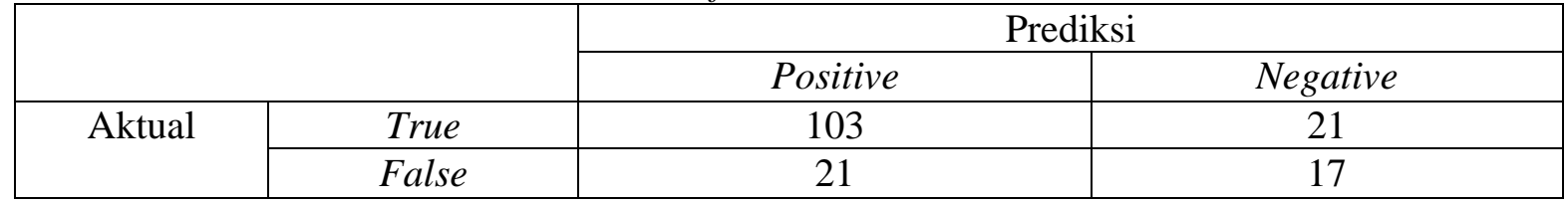

Tabel 6 Confusion Matrix Skenario 2

\begin{tabular}{|c|c|c|c|}
\hline \multirow{2}{*}{\multicolumn{2}{|c|}{}} & \multicolumn{2}{|c|}{ Prediksi } \\
\cline { 3 - 4 } & Positive & Negative \\
\hline \multirow{2}{*}{ Aktual } & True & 96 & 16 \\
\cline { 2 - 4 } & False & 23 & 90 \\
\hline
\end{tabular}

Tabel 7 Confusion Matrix Skenario 3

\begin{tabular}{|c|c|c|c|}
\hline \multirow{2}{*}{\multicolumn{2}{c|}{}} & \multicolumn{2}{|c|}{ Prediksi } \\
\cline { 3 - 4 } & Prue & 102 & Negative \\
\hline \multirow{2}{*}{ Aktual } & True & 22 \\
\cline { 2 - 4 } & False & 22 & 76 \\
\hline
\end{tabular}

Tabel 8 Confusion Matrix Skenario 4

\begin{tabular}{|c|c|c|c|}
\hline \multirow{2}{*}{\multicolumn{2}{|c|}{}} & \multicolumn{2}{|c|}{ Prediksi } \\
\cline { 3 - 4 } Aktual & True & Positive & Negative \\
\cline { 2 - 4 } & False & 97 & 89 \\
\hline
\end{tabular}

Tabel 9 Confusion Matrix Skenario 5

\begin{tabular}{|c|c|c|c|}
\hline \multirow{2}{*}{\multicolumn{2}{|c|}{}} & \multicolumn{2}{|c|}{ Prediksi } \\
\cline { 3 - 4 } & Prue & 96 & Negative \\
\hline \multirow{2}{*}{ Aktual } & True & 16 \\
\cline { 2 - 4 } & False & 23 & 90 \\
\hline
\end{tabular}

Tabel 10 Confusion Matrix Skenario 6

\begin{tabular}{|l|c|c|c|}
\hline \multirow{2}{*}{\multicolumn{2}{|c|}{}} & \multicolumn{2}{|c|}{ Prediksi } \\
\cline { 3 - 4 } Aktual & True & Positive & Negative \\
\cline { 2 - 4 } & False & 102 & 22 \\
\hline
\end{tabular}

HASIL PENELITIAN

Dari penelitian yang sudah dilakukan sesuai skenario dihasilkan confusion matrix yang tampak pada tabel 5 hingga tabel 10. Data confusion matrix di atas didapat melalui data testing. Dari confusion matrix seluruh skenario, maka didapatkan daftar performa akurasi data dari model pengolahan data menggunakan algoritma 
terpilih sebagai berikut:

- Tabel 11. Overall Accuracy

\begin{tabular}{cccc}
\hline Skenario & Accuracy & Precision & AUC \\
\hline 1 & 0.811 & 0.831 & 0.868 \\
\hline 2 & 0.827 & 0.807 & 0.898 \\
\hline 3 & 0.802 & 0.823 & 0.866 \\
\hline 4 & 0.827 & 0.802 & 0.896 \\
\hline 5 & 0.827 & 0.807 & 0.897 \\
\hline 6 & 0.802 & 0.823 & 0.866 \\
\hline
\end{tabular}

Penghitungan Precision diambil dari: True Positive (TP) dibagi dengan hasil penjumlahan antara True Positive (TP) dan False Positif (FP). Melihat dari hasi pengukuran accuracy, precision, dan AUC terhadap 200 data testing dengan total 10 atribut menggunakan algoritma Support Vector Machine terlihat bahwa sistem mencapai performa optimal seperti yang diharapkan. Pada skenario pertama menggunakan Pearson Correlation Coefficient dengan 6 atribut mempunyai hasil accuracy sebesar 0.811 dengan precision 0.831 . Skenario kedua menggunakan Mutual Information dan 6 atribut mendapatkan hasil accuracy sebesar 0.827, precision 0.807 dengan AUC sebesar 0.898. Untuk skenario ketiga menggunakan Pearson Correlation Coefficient dan 8 atribut, mempunyai nilai accuracy lebih rencah dari skenario pertama dan kedua yaitu 0.802 dan precision 0.823 serta AUC 0.866. Untuk skenario keempat menggunakan Mutual Information dan 8 atribut mempunyai hasil accuracy sebesar 0.827 precision lebih rendah dari scenario sebelumnya yaitu 0.802 dan AUC sebesar 0.896. Pada scenario

kelima menggunakan Pearson Correlation Coefficient dan semua atribut menghasilkan accuracy sebesar 0.827, precision 0.807 dengan AUC sebesar 0.897 sedangkan untuk scenario keenam hasil accuracy sebesar 0.802 , precision 0.823 dengan AUC sebesar 0.866. Dari keseluruhan scenario tersebut dapat diihat hasil accuracy terbaik didapat pada scenario kedua, ketiga dan keempat. Namun hasil precision yang terbaik justru pada scenario pertama. Lain halnya untuk tiga hasil AUC terbaik diperoleh melalui scenario kedua lalu kelima dan keempat.

\section{KESIMPULAN}

Melihat hasil penelitian yang sudah dilakukan dapat diambil kesimpulan sebagai berikut :

1. Penggunaan algoritma SVM dengan memilih metode Pearson Correlation Coefficient maupun Mutual Information pada feature selection sudah sesuai dengan hasil accuracy optimal yang diharapkan yaitu lebih dari 0.8. Begitu juga dengan hasil precision serta AUC. Hal ini membuktikan penggunaan Feature Selection pada Azure Machine Learning membawa dampak positif dalam penelitian klasifikasi seperti percobaan ini.

2. Faktor-faktor yang relevan dengan prestasi mahasiswa pada tahun pertama perkuliahan berdasarkan hasil Precision terbaik adalah beasiswa, nilai kimia, nilai matematika, nilai biologi, ekstrakurikuler dan nilai fisika. Hasil tersebut sesuai urutan nilai bobot masing-masing atribut yang didapat pada percobaan.

3. Hasil dari keseluruhan percobaan yang telah dilakukan belum mencapai nilai maksimum yaitu diatas 0.9 seperti yang diharapkan karena keterbatasan jumlah dan kualitas data yang digunakan.

Penelitian menggunakan Microsoft Azure ini masih mungkin dikembangkan terutama dengan memilih menggunakan algoritma Machine Learning yang lain seperti Logistic Regression, Decision Forest dan lainnya dengan jumlah data uji yang lebih banyak dan berkualitas. Selain itu disarankan untuk menambah jumlah atribut sehingga hasil akurasi yang diperoleh dapat lebih baik lagi.

\section{DAFTAR REFERENSI}

[1] Lusi Ariyani, 2016, "Kajian Penerapan Model C45, Support Vector Machine (SVM), dan Neural Network dalam Prediksi Kenaikan Kelas", Faktor Exacta 9(1): 72-86, 2016. ISSN: 1979-276x.

[2] Fahriah, Sirli dan Heru Agus Santoso. Penerapan Algoritma ID3 untuk perediksi Minat Studi Mahasiswa Teknik Informatika Pada Universitas Dian Nuswantoro.

[3] Ahmad, Iftikhar. Basheri, Mohammad and Iqbal, Muhammad Javed. 2018, "Performance Comparison on Support Vector Machine, Random Forest, and Extreme Learning Machine for Intrusion Detection", IEEE Access Volume 6, 2018.

[4] Li, Jundong and Liu, Huan, 2017, "Challenges of Feature Selection for Big Data Analytics". IEEE Computer Society, March/April 2017. 
[5] Zollanvari, Amin. Kizilirmak, Refik Caglar, Kho, Yau Hee and Torrano, Daniel Hernandez, 2018, "Predicting Students' GPA and Developing Intervention Strategies Based on Self-Reglatory Learning Behaviors". IEEE Access, Volume 5, 2017.

[6] Yin, Y., Han, D., \& Cai, Z. (2011). Explore Data Classification Algorithm Based on SVM and PSO for Education Decision. Journal of Convergence Information Technology, 6(10), 122-128.

[7] Betha Nurina Sari, 2017, "Prediksi Performa Akademik Siswa Pada Pelajaran Matematika Menggunakan Bayesian Networks dan Algoritma Klasifikasi Machine Learning", KNPMP II, Universitas Muhammadiyah Surakarta. ISSN: 2502-6526.

[8] http://aryatryasthana.blogspot.com/2015/10/tugas-v-cloud-computing-e-commerce-dan.html diakses pada 28 September 2018.

[9] Sembiring, S., Zarlis, M., Hartama, D., Ramliana, S., \& Wani, E. (2011). Prediction of Student Academic Performance By an Application of Data Mining Techniques. International Conference on Management and Artificial Intelligence (IPEDR), 6, 110-114.

[10] Punlumjeak, Wattana. Rachburee, Nachirat and Arunrerk, Jedsada. "Big Data Analytics: Student Performance Prediction Using Feature Selection and Machine Learning on Microsoft Azure Platform", Journal of Telecommunication, Electronic and Computer Engineering. Vol.9 No.1-4. 